\title{
Regulation and Decriminalisation of Illegal Substances in Thailand
}

\author{
Rasmon Kalayasiri, M.D. ${ }^{1,2}$, Teerayuth Rungnirundorn, M.D. ${ }^{1,2}$, Robert Ali, M.D. ${ }^{3}$, \\ John Marsden, Ph.D. ${ }^{4}$ \\ ${ }^{1}$ Department of Psychiatry, Faculty of Medicine, Chulalongkorn University, ${ }^{2}$ Department of Psychiatry, \\ King Chulalongkorn Memorial Hospital, Pathumwan, Bangkok 10330, Thailand. \\ ${ }^{3}$ University of Adelaide, Adelaide, South Australia 5005, Australia. \\ ${ }^{4}$ Institute of Psychiatry, Psychology \& Neuroscience, King's College, Strand, London WC2R 2LS, United Kingdom. \\ Received 18 October 2018 • Revised 3 January 2019 • Accepted 9 January 2019 • Published online 4 March 2019
}

\section{Abstract:}

Psychoactive substances - chemical compounds which can alter a person's mood, thoughts, and behaviors may be liable to misuse and cause addiction. Internationally, many strategies have been implemented in order to limit the supply and demand of illegal substances, with a wide variation at the country level. Thailand is an upper-middle income country in Southeast Asia. Since 2015, Thai authorities and policymakers have instituted many changes to the legal controls on illegal drugs. The aim of this review was to summarise the history of drug control and regulation in Thailand, focusing on opioids (including Kratom), methamphetamines and cannabis, and the outcome of recent strategies. Recent measures towards decriminalising substance use disorders are also discussed.

Keywords: decriminalisation, drugs, policy, regulation, Thailand

Contact: Assoc. Prof. Rasmon Kalayasiri, M.D.

Department of Psychiatry, Faculty of Medicine, Chulalongkorn University,

Pathumwan, Bangkok 10330, Thailand.

E-mail: Rasmon.k@chula.ac.th
J Health Sci Med Res 2019;37(2):157-162 doi: 10.31584/jhsmr.201943 www.jhsmr.org 


\section{Thailland's legal acts on drugs or illegal sub- stances}

Some psychoactive substances are addictive ${ }^{1}$ and widely used without prescription. Though different strategies to limit illegal substance use have been seen at the international level ${ }^{2,3}$, each country enacts its own strategies to tackle this problem. This article aims to illustrate the history of drug regulation in Thailand using specific strategies from ancient times to the present era.

\section{Ayutthaya and early Rattanakosin: the opium control}

Dating back to the reign of King Authong (the first king of Ayutthaya ${ }^{4}$ ) in 1360, the first formal legal document on opium in Thailand's history banned the trade and use of opium and instituted fines and custodial punishments for lawbreakers. The acknowledgment of the harmful effects of opium use during that era was clearly evidenced by launching this opium regulation (Table 1). In the Rattanakosin period, the prohibition continued during the reign of King Rama I, and there were further and more severe punishments during the reigns of King Rama II and King Rama III. In 1839, an epidemic of opium use was believed to be due to Chinese merchants who became addicted to opium while selling opium from India to Chinese people on behalf of the British. In response, King Rama III ordered a restricted operation to control and eradicate the problem at the time when the Chinese secret society (i.e., Ung-Yee) took control of criminal activity, including opium trading.

A new strategy to control opium use was introduced during the reign of King Rama IV (1851-1868). ${ }^{5}$ He judged that the goal of eradication was not proving successful. He decreed that only Chinese people were permitted to use and trade opium and levied a high tax. This resulted in opium trading being ranked as the fifth highest revenue to the country at that time. In Thailand (as elsewhere) in 1958, it remained lawful to possess opium for trading but possession for consumption was prohibited. However, the revolutionary council subsequently decided to completely prohibit the use and trade of opium. The death sentence could be applied to people trading opium and the council closed opium houses, then treatment and rehabilitation of people with opium addiction was promoted.

\section{Late Rattanakosin: the development of laws and regulations and the rise of methamphe- tamines}

The Narcotics Control Board of Thailand was founded in 1961, at the same time as the first Single Convention on Narcotic Drugs was issued. In $1976^{6}$ the Board's name was changed to the Office of Narcotics Control Board (ONCB) with a mandate to tackle heroin and opium. Subsequently, the Thai government decided to eradicate opium cultivation with American assistance provided by its special military service. Thus, help was provided to the hill tribe villagers, who made their living cropping opium, by replacing the illegal opium cultivation with other commercial plants that were judged to be legally, socially, and medically safer. ${ }^{7}$ At that time, the epidemics of opium and heroin appeared to subside, with the exception of regions in the northern provinces where heroin and opium remained problematic, although not at the level of an epidemic.

In the meantime, in contrast with the decline of opium cultivation ${ }^{8}$, other drugs such as methamphetamines emerged as serious problems in Thailand, as well as other southeast Asian countries. Since then the context of drug problems in Thailand has changed considerably. There are complex reasons for these changes, including the impact of policy, behavioral changes of drug traders, shifting attitudes and behaviors among drug users (especially new young adults and adolescents).

In 1979, the Narcotics Act was issued, classifying heroin as a Schedule I drug and prohibiting all use. Later, 
the government observed the increased prevalence of ya-ma or ya-khayan (i.e., pharmaceutical products containing methamphetamines) causing psychosis. At the time, these drugs were popular among truck drivers and those who wanted to stay awake at night, such as college students, and were associated with increased rates of risky behaviors. ${ }^{9}$ Therefore, in 1996, the government changed the name of ya-ma (horse pill) or ya-khayan (diligent pill) to ya-ba (crazy pill), and also changed the class of the drug to Schedule I. ${ }^{9}$ In part, it would appear that this action was taken to warn people of the serious psychiatric effects, such as going crazy, of using ya-ba. However at the time, ya-ba/ya-ma became more popular among illegal drug users as the prevalence of opioid use fell. It is not known whether the current epidemic of ya-ba is due, at least in part, to the indirect advertisement caused by moving the class of the drug to Schedule I. However, it is also important to note that the relative cost of heroin in the illicit market was much higher compared to methamphetamines. Consequently, it was regulated by economic accessibility, while the price for methamphetamines or ya-ba remained considerably cheaper than opioids, though much higher than the cost of the actual manufacturing process. Taken together, ya-ba may have become more popular than opioids and replaced the prevalence of opioids because of the lower price (economic accessibility) and the unintentional status gained from the policy change.

The effects of the above measures were difficult to see directly because there was no database tracking the prevalence of drug consumption among the teenage and adult populations. In response, a survey by an ONCBfunded academic network from universities with expertise in substance abuse and addiction was developed to estimate the number of people using drugs in the country. The Thailand Substance Abuse Academic Network in 2001 reported that $7.8 \%$ of the Thai population had used ya-ba at least once in their lifetime. ${ }^{10}$ This placed Thailand, at that time, at the top of the methamphetamine-use countries in the world.

Table 1 Timeline of drug regulation in Thailand from ancient times to the modern era

\begin{tabular}{|c|c|c|}
\hline Period of time & Importance & Summary \\
\hline $\begin{array}{l}\text { Ayutthaya and early } \\
\text { Rattanakosin (1360s-1960s) }\end{array}$ & The opium control & $\begin{array}{l}\text {-Ban on trade and use of opium and instituted fines and custodial } \\
\text { punishments. } \\
\text {-Promotion of treatment and rehabilitation of people with opium } \\
\text { addiction. }\end{array}$ \\
\hline $\begin{array}{l}\text { Late Rattanakosin } \\
\text { (1960s-2000s) }\end{array}$ & $\begin{array}{l}\text { The development of law } \\
\text { regulation and the rise of } \\
\text { methamphetamine }\end{array}$ & $\begin{array}{l}\text {-The initiation of The Narcotics Control Board in Thailand to tackle } \\
\text { heroin and opium. } \\
\text {-The decline of opium cultivation by replacing opium with other } \\
\text { economic plants. } \\
\text {-The epidemic of methamphetamine (ya-ba) in contrast with the } \\
\text { decline of heroin use. }\end{array}$ \\
\hline $\begin{array}{l}\text { Modern era and trend } \\
\text { toward future (from 2000s } \\
\text { to present) }\end{array}$ & $\begin{array}{l}\text { War on drugs and the } \\
\text { new strategies for drug } \\
\text { regulation }\end{array}$ & $\begin{array}{l}\text {-War on drugs and its adverse effects such as violence, murder and } \\
\text { insecurity. } \\
\text {-The voluntary treatment of drug users, decriminalisation and legali- } \\
\text { sation of medical use of drugs following international trend. }\end{array}$ \\
\hline
\end{tabular}




\section{Modern era: war on drugs and the new strategies for drug regulation}

In 2003, the country declared a war on drugs to tackle the problem, focusing on recruiting drug users to seek compulsory treatment in addition to destroying the routes of drug suppliers as summarised in the Table $1 .{ }^{11}$ However, the implementation of this policy had a severe and unexpected adverse effect. After the war on drugs began, there were several extrajudicial killings of suspected methamphetamine dealers in order to, claimed by police, avoid betrayal by their accomplices. This war on drugs had many serious effects, such as violence and instability, not only on the people who used drugs but also on their families and communities. Consequently, in 2015, Thailand's military government issued an order to give the drug users caught by the police a chance to go free and receive treatment voluntarily. Currently, the new draft of the Narcotics Act is under review. It is predicted that the new draft will relax the punishments on drug users while permitting some substances to be used for medical purposes. The changes will comply with international guidelines that call for the people who use drugs not to be treated as criminals, but as people who require medical, psychological, and social help. For example, in 2016, the United Nations General Assembly Special Session on Drugs issued an agreement stating that decriminalisation is one of the measures necessary to solve the drug problem.

Although control of methamphetamines has been the priority for policymakers, the trend of using addictive plants in Thailand has received increasing attention. Here, the debate has centered on comparing the benefits and costs in order to consider legalising, regulating, or decriminalising the use of some addictive plants. For example, opium is a plant that is considered to cause more harm than good, especially due to its addictive effect and high risk of overdose/poisoning. Therefore, there has not been much debate on whether it should be controlled or forbidden from general use (with the exception of some medicines, such as tincture of opium, which has been used in some clinical addiction treatment settings in Thailand to aid in the detoxification of other opioid use). ${ }^{12}$

\section{The future: the trend of legalisation and} decriminalisation of cannabis and kratom

Cannabis is judged to be less addictive than opium, with a psychological rather than predominantly physical withdrawal syndrome. ${ }^{13}$ While the risk of increasing the propensity of primary psychotic disorders (including schizophrenia) is conclusive ${ }^{14}$, there is weaker evidence that cannabis affects some people because of risks (i.e., vulnerable genes), and there is also mixed evidence that cannabis is helpful for serious medical diseases. ${ }^{15}$ Another potential harmful effect of cannabis is impaired cognitive functioning $^{16}$, especially judgment during intoxication that could increase the incidence of accidents in various situations. Although cannabis is the most commonly used illegal substance globally, due to the potential harm it can cause as mentioned above, the current trend for policymakers abroad (e.g. several states in the United States and some European countries) is to legalise its recreational use under controls; the name of this measure is called "regulation". Alcohol and tobacco are good examples of the measure of "regulation", which has been used to identify a substance as legal but under the control of a licensed retailer. It is proposed that the sale and consumption of cannabis take place at bars and pubs under strict licensing conditions. ${ }^{17}$ In the new draft of the Narcotics Act, there is potential to allow the use of cannabis only for medical use, but not for recreational use (The current law does not allow any use of cannabis in the country.) The impact of the change in policy of moving a drug down a scheduled class or having less control over the drug will need to be monitored. There is a chance of an increase in drug 
use in the population due to a change in the attitude of the population toward seeing the drug as less harmful to oneself, family, or society. However, decriminalisation (i.e., do not charge criminally) of cannabis use could help with the attitude of people toward drug users, although such benefits may be difficult to measure concretely.

There has been a long, ongoing debate about the legalisation (with control or regulation) and decriminalisation of Kratom (or mytragyna speciosa). It is worth noting that Kratom consumption in Thailand appears in 2 forms: chewing the Kratom leaves or using the water extracted from boiling the leaves. ${ }^{18}$ Traditional use is by chewing the leaves. The Kratom water is usually mixed with other psychoactive substances, such as cough syrup, tramadol or codeine, and cola, and is known as the Kratom cocktail. ${ }^{19}$ In addition, there are rumors that some people who use the Kratom cocktail have also put fluorescent or mosquito incense into the mixture.

According to the 2016 survey, Kratom has the highest incidence of misuse in Thailand with $16.6 \%$ of the population having used it within the past year. ${ }^{20}$ Kratom has been more difficult than cannabis for Thailand's policymakers in making a decision about legalisation because Kratom leaf chewing has long been popular in the everyday life of people in some areas. An epidemiological study in a community setting did not report evidence of Kratom being harmful, and it suggested that drug users believed it may even be beneficial to their health, such as helping to treat diabetes mellitus. ${ }^{18}$ However, hospitals in the epidemic regions frequently see patients who use Kratom having psychotic episodes or becoming addicted to the drug with more than just mild withdrawal symptoms. There was also a report from the Thailand Poison Center of several cases of Kratom-induced seizures and withdrawal symptoms. ${ }^{21}$ Consequently, Kratom has not been declared safe by the authorities in Thailand. Nevertheless, traditional Thai medicine claims that Kratom can be used in treatment recipes for the symptoms of fatigue. However, the side effects of psychotic symptoms and addictive/withdrawal symptoms may be prime concerns for the drug's effects on health. The prevalence of psychotic symptoms and addiction among traditional leaf chewing users warrants further investigation. Some chemical structures in Kratom have been registered for a patent by a group of scientists from Japan, it is believed, for use in pain treatments, but again, the safety of this use needs to be studied further.

No final decision about revising the law has been made yet. If the result is to retain the current illegal status of the drug, then a debate concerning the penalty (i.e., criminalise the people who are caught or fine and send them for treatment) should be considered seriously. It needs to be decided whether it is reasonable to charge someone with a crime when an addicted person cannot control his or her own behavior, especially as drug abuse/ dependence is perceived to be a disease. However, this does not apply to separate criminal acts that should still be prosecuted, such as producing and selling drugs, especially those that are harmful to others.

\section{Conclusion}

As elsewhere, Thailand has a long history of addiction problems. Many measures have been advanced with varying success. The current drug situation in Thailand is a live issue. Drug legalisation (with regulation) and decriminalisation is a subject of debate across society. Such a debate should include appraisals of health risks and potential medical benefits, while recognising the complexity of the topic across other spheres.

\section{References}

1. American Psychiatric Association. Diagnostic and statistical manual of mental disorders (DSM-5). $5^{\text {th }}$ ed. Arlington, VA: American Psychiatric; 2013. 
2. McMahon V. UNDCP facing the challenge. Vienna: UN International Drug Control Programme; 1997.

3. United Nations Office on Drugs and Crime. Making the world safer from crime, drugs and terrorism. Slovakia: UN; 2007.

4. Poomchuen W, Kannika N, Kalayasiri R. The changing view of the Thai society on substance situation. Songkhla: Thailand Substance Abuse Academic Network; 2016.

5. The Revenue Department of Thailand. Memento at the openning of the Revenue Department building on $2^{\text {nd }}$ September 1997. Bangkok: The Department; 1997.

6. Office of the Narcotics Control Board. ONCB: Background. Bangkok: ONCB; 1976.

7. Crooker RA. Forces of change in the Thailand opium zone. Geographical Review 1988;78:241-56.

8. McKetin R, McKetin R, Kozel N, McKetin R, Kozel N, Douglas $\mathrm{J}$, et al. The rise of methamphetamine in Southeast and East Asia. Drug Alcohol Rev 2008;27:220-8.

9. Farrell M, Marsden J, Ali R, Ling W. Methamphetamine: drug use and psychoses becomes a major public health issue in the Asia Pacific region. Addiction 2002;97:771-2.

10. The Administrative Committee of Substance Abuse Academic Network. Preliminary report of project estimation of population related with substance abuse: status of drug and substance use: 2001. Bangkok: ONCB; 2002.

11. Roberts M, Trace M, Klein A. Thailand's 'war on drugs'. Oxford: Beckley Foundation Drug Policy Programme; 2004.

12. Arunpongpaisal S, Intharakamhang D, Kalayasiri R. Detoxification. In: Kalayasiri R, Rungnirundorn T, editors. Recommendations for the management and treatment of substancerelated disorders. Bangkok: Chulalongkorn University; 2015; p.64.
13. Smith NT. A review of the published literature into cannabis withdrawal symptoms in human users. Addiction 2002;97: 621-32.

14. Large M, Sharma S, Compton MT, Slade T, Nielssen O. Cannabis use and earlier onset of psychosis: a systematic metaanalysis. Arch Gen Psychiatry 2011;68:555-61.

15. Whiting PF, Wolff RF, Deshpande S, Di Nisio M, Duffy S, Hernandez AV, et al. Cannabinoids for medical use: a systematic review and meta-analysis. JAMA 2015;313:245673.

16. Solowij N, Stephens RS, Roffman RA, Babor T, Kadden R, Miller $\mathrm{M}$, et al. Cognitive functioning of long-term heavy cannabis users seeking treatment. JAMA 2002;287:1123-31.

17. Global Commission on Drug Policy. Taking control: pathways to drug policies that work. Geneva: GCDC; 2014.

18. Tanguay P. Kratom in Thailand. London: International Drug Policy Consortium; 2011.

19. Chittrakarn S, Penjamras P, Keawpradub N. Quantitative analysis of mitragynine, codeine, caffeine, chlorpheniramine and phenylephrine in a kratom (Mitragyna speciosa Korth.) cocktail using high-performance liquid chromatography. Forensic Sci Int 2012;217:81-6.

20. Saingam D. Substance abuse policy in Thailand: current challenges and future strategies. Stanford: Asia Health Policy Program; 2018.

21. Trakulsrichai S, Tongpo A, Sriapha C, Wongvisawakorn S, Rittilert $\mathrm{P}$, Kaojarern $\mathrm{S}$, et al. Kratom abuse in Ramathibodi Poison Center, Thailand: a five-year experience. J Psychoactive Drugs 2013;45:404-8. 